\title{
ARTICLE \\ Activation of peroxisome proliferator-activated receptor $\gamma$ reduces alcohol drinking and seeking by modulating multiple mesocorticolimbic regions in rats
}

\author{
Yannick Fotio ${ }^{1,2}$, Anna Maria Borruto iD ${ }^{1}$, Federica Benvenuti ${ }^{1}$, Gregory Demopulos ${ }^{3}$, George Gaitanaris ${ }^{3}$, Marisa Roberto ${ }^{4}$ and \\ Roberto Ciccocioppo ${ }^{1}$
}

Peroxisome proliferator-activated receptor $\gamma$ (PPAR $\gamma)$ is an intracellular transcription factor whose signaling activation by the selective agonist pioglitazone reduces alcohol drinking and alcohol-seeking behavior in rats. The present study utilized the twobottle choice and operant self-administration procedures to investigate neuroanatomical substrates that mediate the effects of PPARy agonism on alcohol drinking and seeking in msP rats. Bilateral infusions of pioglitazone $(0,5$, and $10 \mu \mathrm{g} / \mu \mathrm{l}) \mathrm{in}$ the rostromedial tegmental nucleus (RMTg) decreased voluntary alcohol drinking and alcohol self-administration. Microinjections of pioglitazone in the ventral tegmental area (VTA), central amygdala (CeA), and nucleus accumbens (NAc) shell had no such effect. Notably, water, food, and saccharin consumption was unaltered by either treatment. The yohimbine-induced reinstatement of alcohol seeking was prevented by infusions of pioglitazone $(0,2.5,5$, and $10 \mu \mathrm{g} / \mu \mathrm{l})$ in the CeA, VTA, and RMTg but not in the NAc shell. These results emphasize the involvement of mesocorticolimbic circuitries in mediating the effects of PPARY agonists on alcohol drinking and seeking. These results will facilitate future studies that investigate the pathophysiological role of PPAR $y$ in alcohol use disorder and help clarify the mechanisms by which the activation of this receptor decreases the motivation for drinking.

Neuropsychopharmacology (2021) 46:360-367; https://doi.org/10.1038/s41386-020-0754-4

\section{INTRODUCTION}

Alcohol use disorder (AUD) is a chronic brain disease that is characterized by compulsive alcohol drinking and withdrawal symptoms when access to alcohol is prevented, thus heightening the risk of relapse to pathological drinking [1]. AUD is considered the fifth highest risk factor for premature death and disability worldwide. In 2016 alone, more than 3 million deaths and 132.6 million disability-adjusted life years at the global level were attributable to AUD. The neurobiological mechanisms that underlie AUD are still only partially understood but are thought to be associated with profound counteradaptive alterations of reward and stress neurocircuitries [2, 3]. Untangling these neuroadaptations is complex but essential to develop more efficacious therapies.

Peroxisome proliferator-activated receptor $\gamma$ (PPAR $\gamma)$ is a ligandactivated transcription factor that belongs to a large group of nuclear receptors. Upon activation, PPARY regulates gene expression by translocating to the nucleus and binding to a selective DNA sequence called PPAR response element [4]. Although PPARY is mainly expressed in adipose tissue and macrophages where it controls metabolism and the immune response $[5,6]$, recent studies showed that this nuclear factor is also densely expressed in the central nervous system. PPARy is highly expressed in neurons and glial cells where it is involved in neuroprotection, cell repair, and antiinflammatory responses [7-10]. Earlier studies showed that PPARy is expressed on dopaminergic cells in the ventral tegmental area (VTA), suggesting that this receptor could be involved in modulating the reinforcing effects of drugs of abuse [10]. Consistent with this hypothesis, research in our laboratory showed that the systemic administration of two selective PPARy agonists, pioglitazone, and rosiglitazone, significantly reduced alcohol drinking and seeking in alcohol-preferring rats $[11,12]$. However, the neurocircuitries and putative mechanisms that subserve such effects are still unknown. The present study investigated the neuroanatomical substrates that mediate the effects of PPARy agonists on alcohol drinking and seeking to facilitate future characterizations of their molecular and cellular mechanisms.

\section{MATERIALS AND METHODS}

Animals

In total, 10-11-week-old male Marchigian Sardinian alcoholpreferring $(\mathrm{msP})$ rats $\left(N_{\text {total }}=135\right)$, weighing $250-280 \mathrm{~g}$, were employed in this study. They were bred and housed under a reverse $12 \mathrm{~h} / 12 \mathrm{~h}$ light/dark cycle (light on at 8 p.m.) in the vivarium of the University of Camerino and controlled temperature $\left(22^{\circ} \mathrm{C}\right)$ and humidity (55\%). Food (4RF18, Mucedola, Settimo Milanese, Italy) and water were provided ad libitum. Before starting the experiments, the rats were pair housed in conventional clear plastic cages with standard bedding. The experiments were conducted during the dark phase of the light/dark cycle, and

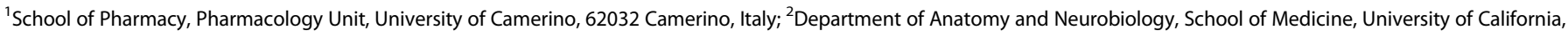
Irvine, CA 92617, USA; ${ }^{3}$ Omeros Corporation, Seattle, WA 98101, USA and ${ }^{4}$ Department of Molecular Medicine, The Scripps Research Institute, La Jolla, CA 92037, USA
} Correspondence: Roberto Ciccocioppo (roberto.cicccocioppo@unicam.it)

Received: 10 March 2020 Accepted: 24 June 2020

Published online: 1 July 2020 
the procedures were conducted in accordance with directives on the care and use of laboratory animals of the European Community Council and National Institutes of Health. Formal approval was obtained from the Italian Ministry of Health and Internal Ethical Committee for Laboratory Animal Protection and Use of the University of Camerino. All efforts were made to minimize the rats' suffering and distress.

\section{Chemicals and treatments}

Saccharin (Sigma, Italy) was dissolved in tap water to obtain a $0.2 \%$ (w/v) solution. Alcohol (Carsetti, Camerino, Italy) was diluted with tap water to obtain a $10 \%$ concentration. The selective PPARy agonist pioglitazone $\left(\mathrm{ED}_{50}=0.2-0.6 \mu \mathrm{M}\right.$ at PPARy inactive at PPARa and PPAR $\delta$ at $10^{-3}$ ) [13-15] was purchased from Molcan Corporation (Richmond Hill, ON, Canada) and dissolved in vehicle that consisted of $10 \%$ dimethylsulfoxide, $3 \%$ Tween 80 , and $87 \%$ distilled water. To evaluate the effects of intracranial pioglitazone administration on alcohol drinking and seeking, the rats were treated twice with the compound: at the onset of the light cycle (8:00 p.m.) and $15 \mathrm{~min}$ before the dark cycle began, when alcohol was made available. The pioglitazone administration schedule was based on previous studies $[11,12]$. Yohimbine (Sigma, Milano, Italy) was dissolved in saline and was used to evoke the reinstatement of alcohol seeking [16]. It was administered intraperitoneally (i.p.) at a dose of $1.25 \mathrm{mg} / \mathrm{kg}, 15 \mathrm{~min}$ after the second injection of pioglitazone and corresponding to the beginning of the dark phase (8:00 a.m.). Reinstatement testing was performed $30 \mathrm{~min}$ after the yohimbine injection. To minimize the diffusion of pioglitazone from the injection site, it was administered in a volume of $0.3 \mu \mathrm{l}$ per site in the rostromedial tegmental nucleus (RMTg) and VTA. In the nucleus accumbens (NAc) shell and central amygdala (CeA), the injection volume was $0.5 \mu \mathrm{l}$ per site. All of the treatments were administered in a counterbalanced Latin-square design to limit the number of rats used.

\section{Intracranial surgery}

The rats were anesthetized by an intramuscular injection $(100-150 \mu \mathrm{l})$ of a solution that contained tiletamine $(58.17 \mathrm{mg} /$ $\mathrm{ml})$ and zolazepam $(7.5 \mathrm{mg} / \mathrm{ml})$. Bilateral guide cannulas $(0.65 \mathrm{~mm}$ outer diameter) that were aimed at the CeA, VTA, RMTg, and NAC shell were implanted and cemented to the skull. We used the following stereotaxic coordinates (from bregma) according to previous reports $[17,18]$ : CeA (anterior/posterior, $-1.8 \mathrm{~mm}$; dorsal/ lateral, $\pm 4.3 \mathrm{~mm}$; medial/ventral, $-7.0 \mathrm{~mm}$ ), VTA (anterior/posterior, $-5.8 \mathrm{~mm}$; dorsal/lateral, $\pm 2.2 \mathrm{~mm}$; medial/lateral, $-7.4 \mathrm{~mm} ; 12^{\circ}$ angle), RMTg (anterior/posterior, $-6.7 \mathrm{~mm}$; dorsal/lateral, \pm 2.2 $\mathrm{mm}$; medial/ventral, $-7.4 \mathrm{~mm} ; 12^{\circ}$ angle), NAc shell (anterior/ posterior, $+1.4 \mathrm{~mm}$; dorsal/lateral, $\pm 0.9 \mathrm{~mm}$; medial/ventral, -6.1 $\mathrm{mm})$. After surgery, the rats received a single subcutaneous injection of ketoprofen $(2.5 \mathrm{mg} / \mathrm{kg})$ and allowed to recover for 1 week in their home cage. During this period, the rats were handled daily and habituated to the injection procedure, consisting of inserting a stainless-steel injector into the guide cannulas, for at least 3 days before the tests began. The injector was $1.5 \mathrm{~mm}$ longer than the guide cannula and left in place for an additional $20 \mathrm{~s}$ after the injection to allow diffusion of the solution. Upon completion of the experiments, the rats were anesthetized with isoflurane, and black India ink ( $0.5 \mu$ l per site) was injected into the studied brain areas. The rats were then immediately euthanized to remove the brain and histologically analyze the cannula placements.

\section{Two-bottle choice procedure}

The two-bottle choice (2-BC) procedure (free choice between water and $10 \%$ alcohol) was used to measure voluntary alcohol drinking and preference [19]. The rats were single housed in experimental chambers $(30 \mathrm{~cm}$ length $\times 30 \mathrm{~cm}$ width $\times 30 \mathrm{~cm}$ height) for 1 week of habituation before beginning the 2-BC test. They were given free access to water and $10 \%$ alcohol $(\mathrm{v} / \mathrm{v})$ for the next 15 days to establish a stable baseline and preference for

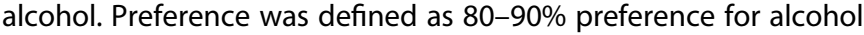
vs. water. The fluids were offered through graduated drinking tubes that were equipped with metal spouts. Fluid intake was measured by reading the volume that was consumed at specific time points $(2,8$, and $24 \mathrm{~h})$ following initiation of the active (dark) phase of the light/dark cycle. The drinking tubes were switched daily to avoid the development of side preference. The rats also had free access to food. Food consumption was measured by weighing the food container while considering the spillage weight. Alcohol, water, and food intakes were calculated as absolute values of consumption at each time-point and are expressed as $\mathrm{g} / \mathrm{kg}$ body weight [20].

\section{Operant alcohol and saccharin self-administration}

Operant chambers were used in daily 30 -min sessions to establish alcohol and saccharin self-administration under fixed-ratio 1 (FR1) schedule of reinforcement [21, 22]. Each chamber was equipped with an active lever and an inactive lever that were symmetrically centered on the side panel. Responding at the active lever activated the infusion pump and released $0.1 \mathrm{ml}$ of $10 \%$ alcohol $(\mathrm{v} / \mathrm{v})$ or $0.2 \%$ saccharin $(\mathrm{w} / \mathrm{v})$ in a liquid receptacle that was located between the two levers. Presses at the inactive lever were recorded but did not activate the infusion pump. During the infusion, a stimulus light that was located above the active lever was turned on for a $5 \mathrm{~s}$ timeout period. Lever pressing during the timeout period was recorded but did not lead to further infusions. When the rats achieved a stable baseline of self-administration for both alcohol and saccharin over the last 3 days of training, we evaluated the effects of microinfusions of pioglitazone in the RMTg every 4 days using a counterbalance Latin-square design.

Yohimbine-induced reinstatement of alcohol seeking The reinstatement experiments consisted of three phases: training for alcohol self-administration, extinction (during which alcohol was no longer available), and reinstatement tests.

In the training phase, alcohol self-administration was performed as described previously (see "Operant alcohol and saccharin selfadministration" section above). Lever responding under the FR1 schedule was maintained for 10 days (sessions) before and after surgery to reestablish baseline alcohol self-administration.

In the extinction phase, after the last alcohol self-administration session, the rats underwent 15 days of extinction sessions, during which they were placed under environmental conditions that were similar to the alcohol training phase, with the exception that responding at the active lever did not result in alcohol deliveries. During the last 3 days of extinction, the rats were habituated to the intracranial treatment procedures.

In the reinstatement phase, the experimental conditions were identical to the extinction phase, but the rats were subjected to a reinstatement test. In separate experiments, pioglitazone $(2.5,5$, and $10 \mu \mathrm{g} / \mu \mathrm{l})$ or its vehicle was injected in the CeA, VTA, RMTg, and NAc shell. The experiment was conducted in a counterbalanced Latin-square design, with a 4-day interval between test sessions. During this interval, the rats were subjected to extinction sessions. The dose of yohimbine and experimental design were based on previous studies [11, 23, 24].

\section{Statistical analyses}

The data were analyzed using analysis of variance (ANOVA) followed by the Newman-Keuls multiple-comparison post-hoc test when appropriate. The effects of intracranial injections of pioglitazone in the CeA, VTA, RMTg, and NAc shell on alcohol, water, and food intake were analyzed using two-way repeatedmeasures ANOVA, with time and treatment as within-subjects factors. The effects of microinfusions of pioglitazone in the RMTg on alcohol and saccharin self-administration were analyzed using one-way repeated-measures ANOVA, with treatment as the 

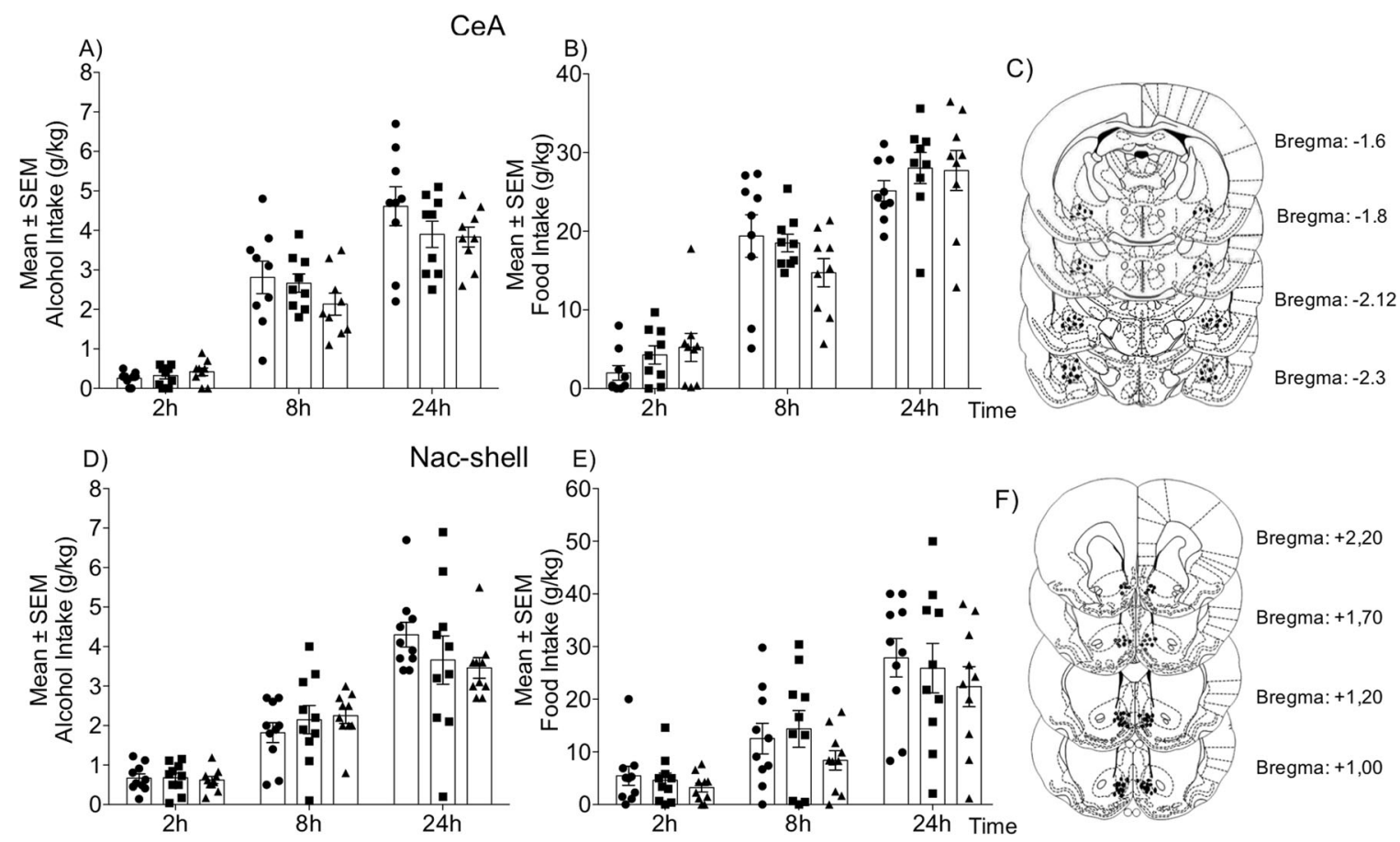

Fig. 1 Effect of intra-CeA and intra-NAc shell pioglitazone administration on alcohol and food intake in msP rats. a, $d$ Time-course of alcohol drinking following pioglitazone administration in the CeA and NAc shell, respectively. $\mathbf{b}$, e Changes in food intake following treatment. Schematic illustration of vehicle and pioglitazone injection sites (dots) in the CeA (c) and NAc shell (f). The data are expressed as mean ( \pm SEM) intake. $n=9$ for CeA. $n=11$ for NAc shell.

within-subjects factor. The effects of microinfusions of pioglitazone in the CeA, VTA, RMTg, and NAc shell on the yohimbineinduced reinstatement of alcohol seeking were analyzed using one-way repeated-measures ANOVA, with treatment as the within-subjects factor. For the reinstatement experiments, differences between lever responding during the extinction and reinstatement sessions were analyzed using paired Student's $t$ test. The 2-BC data are expressed as the mean ( \pm SEM) of intake ( $g$ / $\mathrm{kg}$ of body weight). For operant self-administration, the data are expressed as the mean $( \pm$ SEM) of the number of responses at the active and inactive levers. Only data from rats with correct cannula placements were included in the statistical analyses. The following numbers of rats were included in the statistical analyses: voluntary alcohol drinking (CeA, $n=9$; VTA, $n=11$; RMTg, $n=11$; NAc shell, $n=10$ ), alcohol self-administration (RMTg, $n=8$ ), saccharin selfadministration (RMTg, $n=16$ ), reinstatement of alcohol seeking (CeA, $n=12$; VTA, $n=10$, RMTg, $n=15$ : NAc shell, $n=13$ ). The statistical analyses were performed using Prism 8.0 software (GraphPad, La Jolla, CA, USA). Values of $p<0.05$ vs. the vehicle control were considered statistically significant.

\section{RESULTS}

Effect of intra-CeA activation of PPARy on voluntary 2-BC alcohol drinking

Pioglitazone ( 5 and $10 \mu \mathrm{g} / \mu \mathrm{l}$ ) was microinfused in the CeA in msP rats in a counterbalanced Latin-square design $(n=9)$. As shown in Fig. 1a, voluntary alcohol drinking was monitored at 2,8 , and $24 \mathrm{~h}$. The overall ANOVA revealed no difference in the amount of alcohol consumption between the pioglitazone- and vehicle-treated groups at any time-point (time: $F_{2,16}=33.91$, $p<0.0001$; treatment: $F_{2,16}=2.492, p=0.344$; time $\times$ treatment interaction: $F_{4,32}=0.7949, p=0.5373$ ). Similarly, no difference in the amount of water (time: $F_{2,16}=8.685, p=0.0028$; treatment: $F_{2,16}=1.311, p=0.2970$; time $\times$ treatment interaction: $F_{4,32}=8834, p=0.4849$; Table S1) or food (time: $F_{2,16}=$
64.11, $p<0.0001$; treatment: $F_{2,16}=6025, p=0.5594$; time $\times$ treatment interaction: $F_{4,32}=2.674, p=0.0946$; Fig. 1b) consumption was found between the pioglitazone- and vehicletreated groups.

Effect of intra-NAc shell activation of PPARY on voluntary 2-BC alcohol drinking

The ANOVA revealed that alcohol consumption was detectable $2 \mathrm{~h}$ after treatment and progressively increased in the following hours (time: $F_{2,18}=78.76, p<0.0001$; Fig. $1 \mathrm{~d}$ ). The ANOVA also revealed that intake were unaffected by treatment, although a slight reduction was observed at $24 \mathrm{~h}\left(F_{2,18}=0.2135, p=0.8098\right)$. No time $\times$ treatment interaction was detected $\left(F_{4,36}=2.067, p=\right.$ 0.1055). Intra-NAc shell pioglitazone administration did not alter the consumption of water (time: $F_{2,18}=11.89, p<0.001$; treatment: $F_{2,18}=0.073, p=0.9298$; time $\times$ treatment interaction: $F_{4,36}=0.3109, p=0.8688$; Table S1) or food (time: $F_{2,18}=54.39$, $p<0.0001$; treatment: $F_{2,18}=0.9515, p=0.4048$; time $\times$ treatment interaction: $F_{4,36}=0.5584, p=0.6942$; Fig. 1e).

Effect of intra-RMTg activation of PPARy on voluntary 2-BC alcohol drinking

Pioglitazone $(5$ and $10 \mu \mathrm{g} / \mu \mathrm{l})$ was microinfused in the RMTg in $\mathrm{msP}$ rats $(n=11)$. The ANOVA revealed significant effects of time $\left(F_{2,20}=104.7, p<0.0001\right)$ and treatment $\left(F_{2,20}=21.27, p<0.0001\right)$ and a significant time $\times$ treatment interaction $\left(F_{4,40}=8.701, p<\right.$ $0.0001)$. As shown in Fig. 2a, voluntary alcohol consumption was detectable but not significantly affected by intra-RMTg pioglitazone administration $2 \mathrm{~h}$ after treatment. However, at 8 and $24 \mathrm{~h}$ post treatment, alcohol intake dose-dependently decreased. Interestingly, intra-RMTg pioglitazone administration did not alter water (time: $F_{2,20}=5.106, p=0.0162$; treatment: $F_{2,20}=1.593, p=$ 0.2280 ; time $\times$ treatment interaction: $F_{4,40}=0.2922, p=0.8813$; Table S1) or food (time: $F_{2,20}=45.21, p<0.0001$; treatment: $F_{2,20}=0.3759, p=0.6914$; time $\times$ treatment interaction: $F_{4,40}=$ $0.1251, p=0.3051$; Fig. 2 b) consumption. 


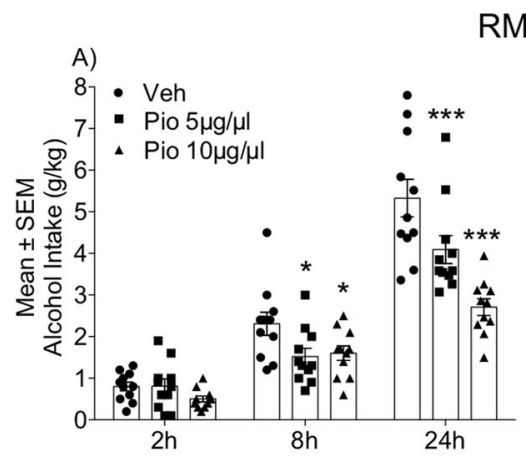

RMTg
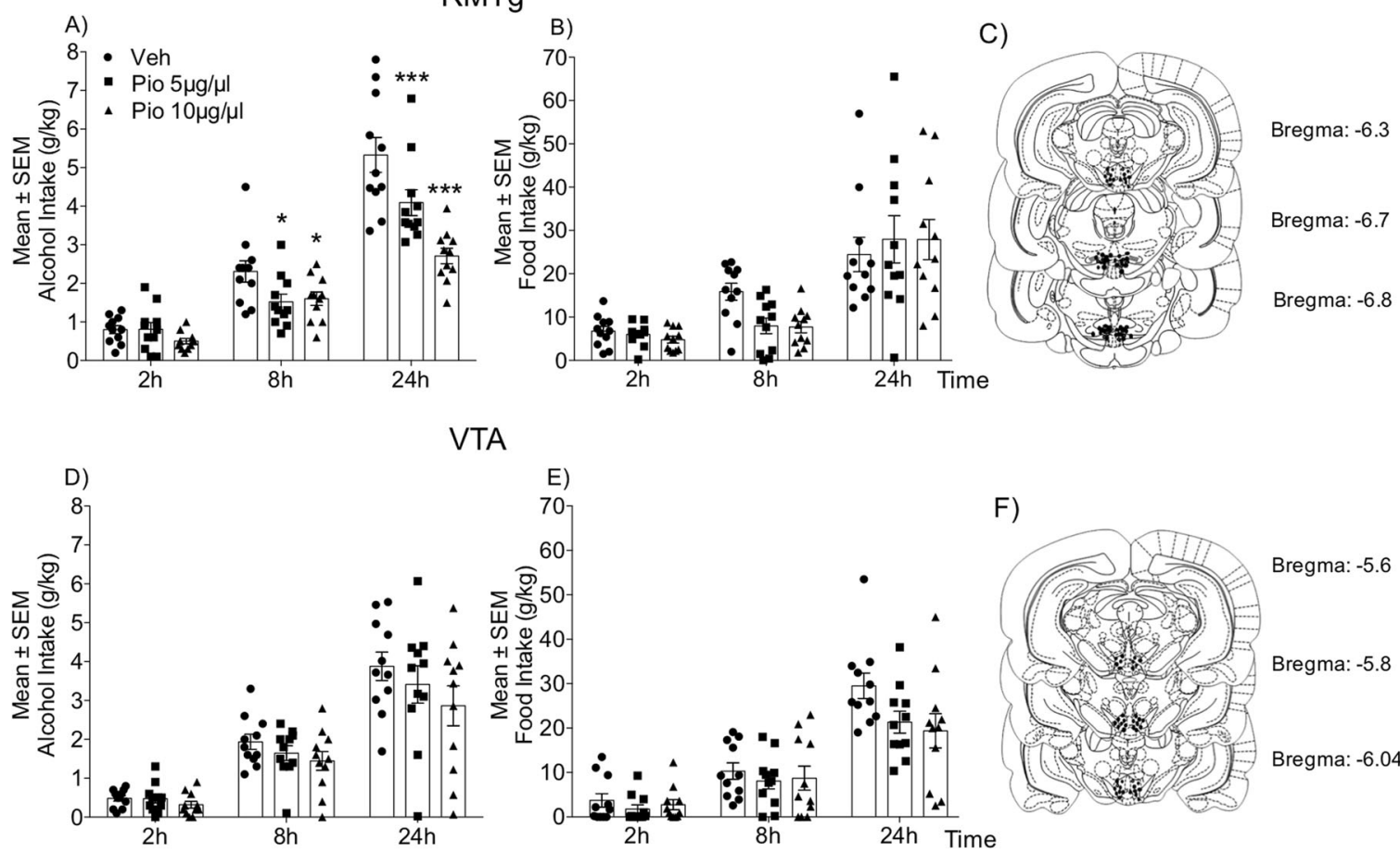

F)

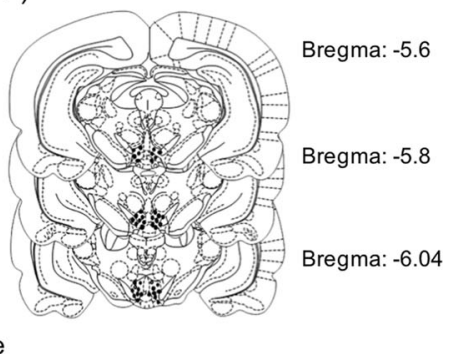

Fig. 2 Effect of intra-RMTg and intra-VTA pioglitazone administration on alcohol, water, and food intake in msP rats. a, $d$ Time-course of alcohol drinking following pioglitazone administration in the RMTg and VTA, respectively. b, e Changes in food intake following treatment. Schematic illustration of vehicle and pioglitazone injection sites (dots) in the RMTg (c) and VTA (f). The data are expressed as mean ( \pm SEM) intake. $n=11$ for RMTg. $n=11$ for VTA. ${ }^{*} p<0.05 ;{ }^{* *} p<0.01 ;{ }^{* * *} p<0.001$, vs. vehicle-treated control.

Effect of intra-VTA activation of PPARy on voluntary 2-BC alcohol drinking

Pioglitazone (5 and $10 \mu \mathrm{g} / \mu \mathrm{l})$ was microinfused in the VTA in msP rats $(n=11)$. Alcohol intake was detectable $2 \mathrm{~h}$ after initiation of the dark phase. The ANOVA revealed a significant effect of time on alcohol intake $\left(F_{2,20}=80.74, p<0.0001\right.$; Fig. $\left.2 d\right)$ but no effect of treatment $\left(F_{2,20}=2.425, p=0.114\right)$ and no time $\times$ treatment interaction $\left(F_{4,40}=0.8606, p=0.4959\right)$. The intra-VTA administration of pioglitazone or its vehicle did not alter the absolute amount of alcohol consumption at any time-point $(2,8$, and $24 \mathrm{~h})$. Treatment did not affect water (time: $F_{2,20}=6.38, p=0.0096$; treatment: $F_{2,20}=0.7005, p=0.5081$; time $\times$ treatment interaction: $F_{4,40}=0.7241, p=0.5807$; Table S1) or food (time: $F_{2,20}=76.40$, $p<0.0001$; treatment: $F_{2,20}=2.178, p=0.1394$; time $\times$ treatment interaction: $F_{4,40}=1.895, p=0.074$; Fig. 2e) consumption.

Effect of intra-RMTg activation of PPARy on alcohol and saccharin self-administration

To further investigate the role of the RMTg in modulating alcohol intake through PPARy, msP rats $(n=8)$ underwent operant alcohol $(10 \%, v / v)$ self-administration training. When they reached a stable mean number of reinforcements earned, pioglitazone ( 5 and 10 $\mu \mathrm{g} / \mu \mathrm{l})$ or its vehicle were administered in the RMTg, and their effects on operant responding were evaluated. As expected, the ANOVA showed that pioglitazone dose-dependently decreased the number of reinforced lever presses $\left(F_{2,14}=6.361, p=0.006\right.$; Fig. 3a). The number of responses at the inactive lever was negligible and did not changed throughout the experiment (Fig. 3b).

To test whether the observed effect of intra-RMTg PPARY activation is selective for alcohol, rats $(n=16)$ were trained to selfadminister saccharin $(0.2 \%, \mathrm{w} / \mathrm{v})$ under an FR1 schedule until they reached a stable baseline of reinforcements obtained. Pioglitazone ( 5 and $10 \mu \mathrm{g} / \mu \mathrm{l}$ ) was then microinfused in the RMTg. The ANOVA revealed that this treatment did not alter saccharin self- administration $\left(F_{2,30}=0.3996, p=0.6748\right.$; Fig. 3c). Responding at the inactive lever was negligible and did not changed throughout the experiment (Fig. 3d).

Effect of intra-CeA activation of PPARy on yohimbine-induced reinstatement of alcohol seeking

Pioglitazone $(2.5,5$, and $10 \mu \mathrm{g} / \mu \mathrm{l})$ or its vehicle were microinfused in the $\mathrm{CeA}$ in $\mathrm{msP}$ rats $(n=12)$ to evaluate its effect on the yohimbine-induced reinstatement of alcohol seeking. During the training phase, the mean number of responses at the active lever was $68.73 \pm 5.95$, which sharply decreased during extinction $(21.41 \pm 1.97)$. Paired Student's $t$ test (vehicle vs. extinction) revealed that yohimbine administration $(1.25 \mathrm{mg} / \mathrm{kg}$, i.p.) significantly reinstated operant alcohol-seeking behavior $\left(t_{11}=3.8, p=\right.$ 0.0029 ; Fig. 4a), which was prevented by intra-CeA infusions of pioglitazone $\left(F_{3,33}=16.12, p<0.0001\right)$. Responding at the inactive lever was low $(1.79 \pm 0.49)$ and not significantly affected by the treatment (Fig. 4b).

Effect of intra-NAc shell activation of PPARY on yohimbineinduced reinstatement of alcohol seeking

In msP rats $(n=13)$ with cannula implants in the NAc shell during the training phase, the mean number of responses at the active lever was $65.33 \pm 5.54$, which significantly decreased during extinction $(19.12 \pm 4.95)$ and was reinstated $\left(t_{12}=5.096, p=\right.$ $0.0003)$ by yohimbine treatment $(1.25 \mathrm{mg} / \mathrm{kg}$, i.p.). However, intraNAc shell pioglitazone administration did not alter the yohimbineinduced reinstatement of alcohol seeking $\left(F_{3,36}=1.838, p=\right.$ 0.1578; Fig. 4d). Responding at the inactive lever was low and unchanged by the treatments (Fig. 4e).

Effect of intra-VTA activation of PPARy on yohimbine-induced reinstatement of alcohol seeking

During the training phase in msP rats $(n=10)$, the mean number of responses at the active lever was $67.87 \pm 6.52$. Operant responding 


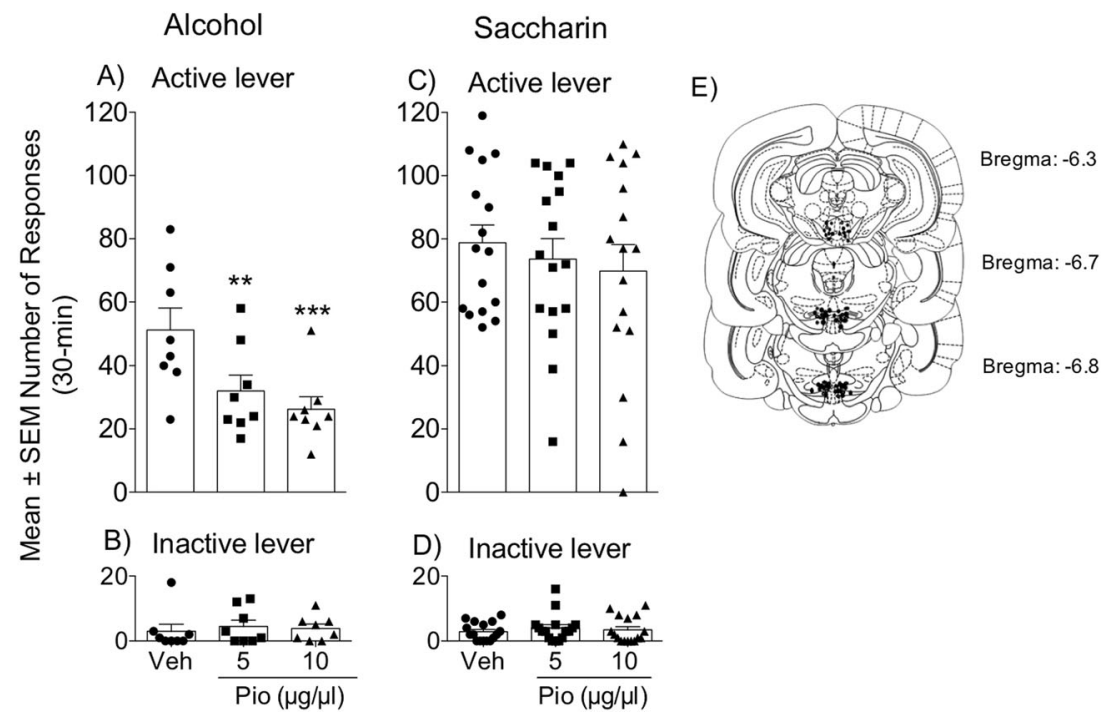

Fig. 3 Effect of intra-RMTg pioglitazone administration on operant alcohol and saccharin self-administration. a, c Number of alcohol and saccharin reinforcements earned following pioglitazone administration in the RMTg. b, d Number of responses at the inactive lever. e Schematic illustration of vehicle and pioglitazone injection sites (dots) in the RMTg. The data are expressed as the mean \pm SEM. $n=8$ for alcohol. $n=16$ for saccharin. ${ }^{*} p<0.05 ;{ }^{* *} p<0.01$, vs. vehicle-treated control.

markedly decreased during extinction (13.63 \pm 1.51 lever presses). As shown in Fig. $5 \mathrm{a}$, treatment with yohimbine $(1.25 \mathrm{mg} / \mathrm{kg}$, i.p.) significantly reinstated $\left(t_{9}=6.552, p<0.0001\right)$ operant responding for alcohol. This effect was dose-dependently prevented by intraVTA pioglitazone administration $\left(F_{3,27}=8.87, p=0.0003\right)$. Responding at the inactive lever was negligible $(4.86 \pm 1.66)$ and not significantly affected by the treatments (Fig. 5b).

Effect of intra-RMTg activation of PPARY on yohimbine-induced reinstatement of alcohol seeking

In msP rats $(n=15)$ with cannula implants in the RMTg, the mean number of responses at the active lever was $72.35 \pm 4.81$ during the training phase, which rapidly decreased during extinction $(19.22 \pm 1.7)$. Yohimbine $(1.25 \mathrm{mg} / \mathrm{kg}$, i.p.) significantly increased the number of responses at the active lever $\left(t_{14}=4.460, p=\right.$ 0.0005 ; Fig. $5 d$ ). This effect was dose-dependently decreased by intra-RMTg pioglitazone administration $\left(F_{3,42}=74.54, p<0.0001\right.$; Fig. $5 d$ ). Responding at the inactive lever (Fig. 5e) was negligible and unaffected by the treatments.

\section{DISCUSSION}

Administration of pioglitazone in the RMTg decreased alcohol intake

The mesocorticolimbic dopamine system which originates in the VTA and projects to the NAc, CeA, and prefrontal cortex. This system plays a key role in controlling the reinforcing properties of drugs of abuse, including alcohol [25-31]. The majority of afferent connections to VTA dopaminergic cells are $\gamma$-aminobutyric acid (GABA)ergic and inhibitory [32-34]. Emerging evidence indicates that the tail of the VTA, also known as the RMTg, provides important GABAergic inputs to VTA dopaminergic cells [32, 3537]. Therefore, the RMTg is a key structure in the development and maintenance of drug addiction. PPARy expression has been detected on VTA dopaminergic neurons [10] and RMTg GABAergic cells [18]. Thus, we investigated whether the effect of pioglitazone on alcohol drinking involves PPARY-dependent signaling in these two adjacent areas. We infused pioglitazone in the VTA and RMTg and evaluated its effect in the 2-BC procedure. We found that PPARY activation in the RMTg but not the VTA significantly attenuated alcohol drinking compared with vehicle-treated rats. Moreover, water and food consumption were unaltered by pioglitazone treatment, indicating that its effect in the RMTg is specific to alcohol and does not generalize to water or food. To confirm this finding, we subsequently administered pioglitazone in the RMTg in two groups of rats that were trained to selfadminister alcohol or saccharin. As expected, pioglitazone significantly attenuated alcohol but not saccharin intake, suggesting that PPARY activation may specifically reduce the motivation for alcohol. Notably, the VTA and RMTg are in anatomical contiguity. Hence, the fact that pioglitazone was efficacious only when injected in the RMTg demonstrated that it did not diffuse to neighboring regions at the dose and volume tested. A corollary to this finding is that the RMTg is the sole neuroanatomical substrate for the alcohol-suppressing effect of PPAR $y$ agonists. This hypothesis was supported by findings that showed that pioglitazone microinfusions in other brain areas of the mesocorticolimbic system where PPARy is expressed (e.g., CeA and NAc shell) did not affect alcohol drinking $[8,38]$. Such a specific role for PPARy activation in the RMTg in controlling the reinforcing effects of drugs of abuse has also been observed in opioid selfadministration studies in our laboratory [18]. In this earlier study, we found that the effect of pioglitazone in the RMTg was linked to its ability to increase the inhibitory tone of RMTg GABAergic cells, thereby inhibiting dopamine neuron activation in the VTA [18]. Although more studies are needed to support this hypothesis, we speculate that a similar mechanism may be involved in the alcohol-suppressing effects of PPARy agonists.

An interesting observation in the present study was that the effect of pioglitazone in the 2-BC test was observed at 8 and $24 \mathrm{~h}$ but not at $2 \mathrm{~h}$. In the operant self-administration experiments, this effect was observed at $30 \mathrm{~min}$. Two possibilities may explain this apparent discrepancy. First, in the operant self-administration session, the rats consumed $\sim 1.25 \mathrm{~g} / \mathrm{kg}$ alcohol in $30 \mathrm{~min}$. In the $2-$ $\mathrm{BC}$ test, the rats had to drink for more than $2 \mathrm{~h}$ to reach this level of consumption. This may result in different pharmacokinetics of the drug (i.e., peak levels in the brain) that in turn may influence the response to pioglitazone. Second, motivation of the animals may be more effectively captured in operant self-administration experiments than in 2-BC experiments. If pioglitazone acts by 

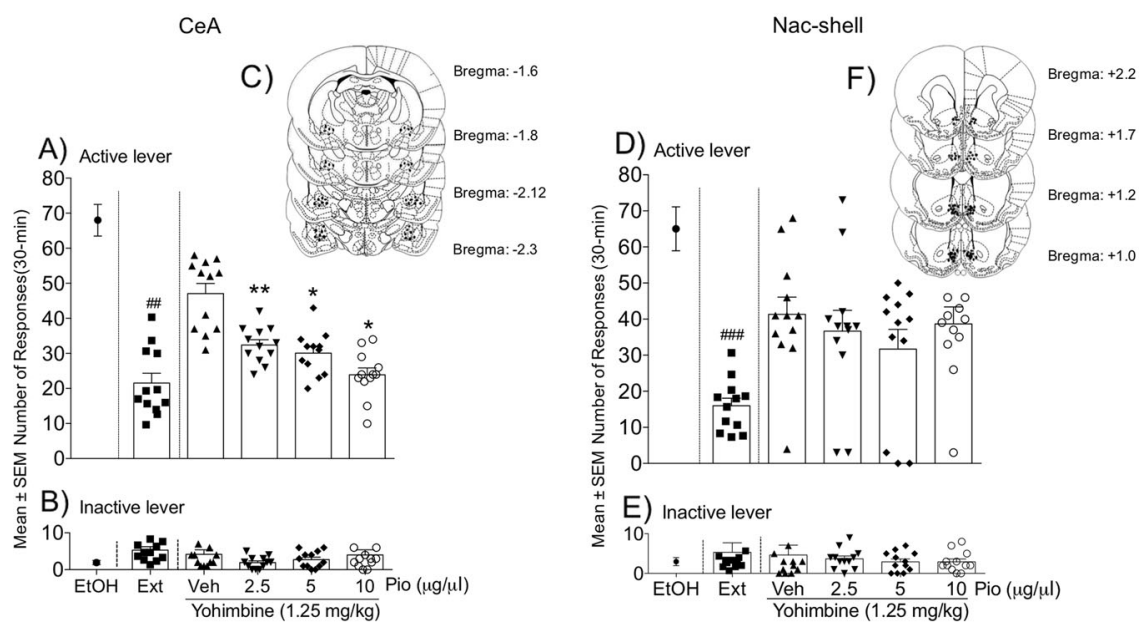

Fig. 4 Effect of intra-CeA and intra-NAc shell pioglitazone administration on the yohimbine-induced reinstatement of alcohol seeking. a, d Number of responses at the active lever following pioglitazone administration in the CeA and NAc shell, respectively. b, e Number of responses at the inactive lever following treatment. Schematic illustration of vehicle and pioglitazone injection sites (dots) in the CeA (c) and NAc shell (f). The data are expressed as mean ( \pm SEM) intake. $n=12$ for CeA. $n=13$ for NAc shell. ${ }^{\# \#} p<0.01$, vehicle vs. extinction; ${ }^{*} p<0.05$; ${ }^{* *} p<0.01$, vehicle- vs. pioglitazone-treated rats.
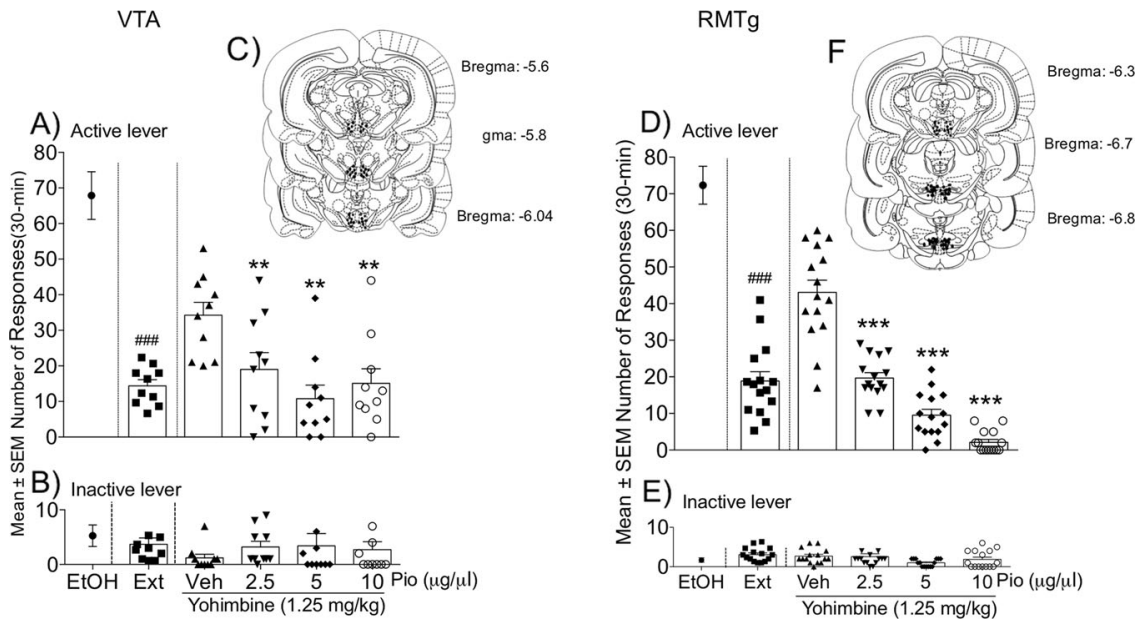

Fig. 5 Effect of intra-RMTg and intra-VTA pioglitazone administration on the yohimbine-induced reinstatement of alcohol seeking. a, $d$ Number of responses at the active lever following pioglitazone administration in the VTA and RMTg, respectively. $\mathbf{b}$, e Number of responses at the inactive lever following treatment. Schematic illustration of vehicle and pioglitazone injection sites (dots) in the VTA (c) and RMTg (f). The data are expressed as mean ( \pm SEM) intake. $n=10$ for VTA. $n=10$ for RMTg. ${ }^{\# \#} p<0.001$, vehicle vs. extinction; ${ }^{* *} p<0.01 ;{ }^{* * *} p<0.001$, vehiclevs. pioglitazone-treated animals.

attenuating the motivation for alcohol, then a more pronounced effect may be observed under operant contingencies rather than under free-drinking conditions.

Administration of pioglitazone in the VTA and RMTg reduced the yohimbine-induced reinstatement of alcohol seeking

The high rate of relapse among individuals with alcohol and substance use disorders is a major clinical problem [39, 40]. Studies that utilized well-validated animal models of drug reinstatement demonstrated that the $a_{2}$-adrenergic receptor antagonist yohimbine increased drug craving in humans [41, 42] and reinstated extinguished alcohol-seeking behavior in rats that were trained to self-administer alcohol [43-45]. Yohimbine reinstates drug seeking through complex mechanisms that partially involve activation of the stress system and the potentiation of responding to sensory cues [46-49]. Consistent with these mechanisms, earlier studies showed that the yohimbine-induced reinstatement of drug seeking was reduced by corticotropin-releasing factor- 1 receptor antagonists and the blockade of dopamine transmission [45, 47, 49-52]. Previous reports from our laboratory showed that systemic PPARy agonist administration prevented the yohimbine- but cue-induced reinstatement of alcohol seeking in msP rats [11, 12]. Here, under identical experimental conditions, we found that PPAR $y$ activation in the RMTg profoundly and dose-dependently decreased the yohimbineinduced reinstatement of alcohol seeking. A similar but less marked effect was also observed following pioglitazone administration in the VTA. PPARY agonists may engage intra-RMTg GABAergic signaling to reduce the firing of VTA dopaminergic neurons [18]. This hypothesis is supported by previous studies that showed that stress strongly activated VTA dopaminergic neurons to induce the reinstatement of drug seeking $[53,54]$. This effect of stress was prevented by intra-VTA administration of the $\mathrm{GABA}_{B}$ receptor agonist baclofen [55]. Moreover, yohimbine-induced reinstatement was blocked by both systemic and intra-medial prefrontal cortex (i.e., a region that receives dopaminergic afferents from the VTA) administration of dopamine receptor antagonists [50-52]. The 
present results demonstrate that the RMTg might play a critical role in the stress-induced reinstatement of alcohol seeking. However, because of the tight apposition of the RMTg and VTA, one possibility is that the effect of pioglitazone on yohimbine-induced alcohol seeking is at least partially attributable to spread of the drug into the nearby VTA. This possibility cannot be excluded, but appears to be unlikely because the effect of pioglitazone was much more pronounced when it was injected directly in the RMTg rather in the VTA. An opposite effect would be expected if the VTA was the main site of action of the drug.

Administration of pioglitazone in the RMTg did not affect operant responding for saccharin

GABAergic neurons in the RMTg are also known to strongly inhibit dopaminergic cells in the substantia nigra compacta, thereby controlling motor coordination and motor learning [56, 57]. Based on evidence that RMTg GABAergic signaling is the main neurocircuitry that mediates the PPAR $y$ agonist-induced reduction of alcohol intake, we considered the possibility that the effects of pioglitazone on lever pressing for alcohol may have been influenced by an influence on locomotor activity. However, when we microinjected pioglitazone in the RMTg in rats that were trained to self-administer saccharin, we found that the number of reinforcements earned was unaffected by the drug. These results indicate that PPARY activation in the RMTg selectively controls alcohol intake and the yohimbine-induced reinstatement of alcohol seeking by modulating the mesocorticolimbic system without altering transmission of the nigrostriatal pathway.

Administration of pioglitazone in the CeA but not NAc shell attenuated the reinstatement of alcohol seeking

Finally, we found that the yohimbine-induced reinstatement of alcohol seeking was attenuated by intra-CeA but not intra-NAc shell (pioglitazone administration). These results suggest that neurocircuitry in the $\mathrm{CeA}$ may also be recruited by PPARY agonists to attenuate the reinstatement of alcohol seeking. This intra-CeA effect of pioglitazone may be secondary to anxiolytic properties of the compound [38]. In fact, it has been demonstrated that the CeA plays an important role in the expression of excessive anxiety linked to stress exposure $[17,58,59]$. Moreover, the pharmacological and genetic blockade of PPARy signaling in the $\mathrm{CeA}$ exacerbated basal anxiety-like behavior and increased the vulnerability to stress [38]. Therefore, a tempting speculation is that the anxiolytic properties of pioglitazone may be partially responsible for the protective effects of PPARY agonists against the stress-induced reinstatement of alcohol seeking.

In conclusion, the present findings filled a gap in the literature by revealing brain areas that modulate the effect of PPARY activation on alcohol-seeking behavior. The results also demonstrate an important role for RMTg in modulating the yohimbine stress-induced reinstatement of alcohol seeking. Pioglitazone is clinically used for the treatment of insulin resistance in patients with type 2 diabetes, and its tolerability has been largely demonstrated [60-62]. Hence, the ability of pioglitazone to decrease alcohol seeking may open new avenues for further clinical investigation of its efficacy.

\section{FUNDING AND DISCLOSURE}

This work was supported by National Institute on Alcohol Abuse and Alcoholism grant AA017447 (to MR and RC) and AA014351 (to FW and RC) by grant (2017SXEXT5) PRIN 2017 (to RC). GD is the Chairman and CEO of Omeros Corporation (Omeros). GG is the Chief Scientific Officer of Omeros. RC is the inventor on several patent applications that are related to the therapeutic use of PPARy agonists for the treatment of addiction. Omeros, through agreements with the University of Camerino and RC, exclusively controls the intellectual property rights that are directed to $\mathrm{RC}^{\prime} \mathrm{s}$ inventions related to the use of PPARy agonists for the treatment of addiction and addictive behaviors. Under these agreements, RC may be entitled to receive payments and royalties from Omeros. The authors declare no competing interests.

\section{ACKNOWLEDGEMENTS}

We are thankful to Amina Aboufares El Alaoui for her help during the experiments, Rina Righi, Alfredo Fiorelli, and Agostino Marchi for animal care and technical support, and Michael Arends for editing the paper.

\section{AUTHOR CONTRIBUTIONS}

$\mathrm{YF}, \mathrm{RC}$, and MR designed the project. YF designed and performed the experiments, analyzed the data, and wrote the paper. AMB and FB performed the experiments and analyzed the data. $\mathrm{RC}$ supervised the project and contributed to writing the paper. MR, GD, and GG provided critical comments, helped interpret the data, and contributed to writing the paper. All of the authors reviewed the paper.

\section{ADDITIONAL INFORMATION}

Supplementary Information accompanies this paper at (https://doi.org/10.1038/ s41386-020-0754-4).

Publisher's note Springer Nature remains neutral with regard to jurisdictional claims in published maps and institutional affiliations.

\section{REFERENCES}

1. Hasin DS, O'Brien CP, Auriacombe M, Borges G, Bucholz K, Budney A, et al. DSM-5 criteria for substance use disorders: recommendations and rationale. Am J Psychiatry. 2013;170:834-51.

2. Gilpin NW, Koob GF. Neurobiology of alcohol dependence: focus on motivational mechanisms. Alcohol Res Health. 2008;31:185-95.

3. Michalak A, Biala G. Alcohol dependence-neurobiology and treatment. Acta Pol Pharm. 2016;73:3-12.

4. Kroker AJ, Bruning JB. Review of the structural and dynamic mechanisms of PPARgamma partial agonism. PPAR Res. 2015;2015:816856.

5. Ferre $P$. The biology of peroxisome proliferator-activated receptors: relationship with lipid metabolism and insulin sensitivity. Diabetes. 2004;53(Suppl 1):S43-50.

6. Matsusue K, Peters JM, Gonzalez FJ. PPARbeta/delta potentiates PPARgammastimulated adipocyte differentiation. FASEB J. 2004;18:1477-9.

7. Villapol S. Roles of peroxisome proliferator-activated receptor gamma on brain and peripheral inflammation. Cell Mol Neurobiol. 2018;38:121-32.

8. Warden A, Truitt J, Merriman M, Ponomareva O, Jameson K, Ferguson LB, et al. Localization of PPAR isotypes in the adult mouse and human brain. Sci Rep. 2016;6:27618.

9. Garrido-Gil P, Joglar B, Rodriguez-Perez Al, Guerra MJ, Labandeira-Garcia JL. Involvement of PPAR-gamma in the neuroprotective and anti-inflammatory effects of angiotensin type 1 receptor inhibition: effects of the receptor antagonist telmisartan and receptor deletion in a mouse MPTP model of Parkinson's disease. J Neuroinflamm. 2012;9:38.

10. Sarruf DA, Yu F, Nguyen HT, Williams DL, Printz RL, Niswender KD, et al. Expression of peroxisome proliferator-activated receptor-gamma in key neuronal subsets regulating glucose metabolism and energy homeostasis. Endocrinology. 2009;150:707-12.

11. Stopponi S, Somaini L, Cippitelli A, Cannella N, Braconi S, Kallupi M, et al. Activation of nuclear PPARgamma receptors by the antidiabetic agent pioglitazone suppresses alcohol drinking and relapse to alcohol seeking. Biol Psychiatry. 2011;69:642-9.

12. Stopponi S, de Guglielmo G, Somaini L, Cippitelli A, Cannella N, Kallupi M, et al. Activation of PPARgamma by pioglitazone potentiates the effects of naltrexone on alcohol drinking and relapse in $\mathrm{msP}$ rats. Alcohol Clin Exp Res. 2013;37:1351-60.

13. Xu HE, Lambert MH, Montana VG, Plunket KD, Moore LB, Collins JL, et al. Structural determinants of ligand binding selectivity between the peroxisome proliferator-activated receptors. Proc Natl Acad Sci USA. 2001;98:13919-24.

14. Chen R, Wan J, Song J, Qian Y, Liu Y, Gu S. Rational screening of peroxisome proliferator-activated receptor-gamma agonists from natural products: potential therapeutics for heart failure. Pharm Biol. 2017;55:503-9.

15. Willson TM, Cobb JE, Cowan DJ, Wiethe RW, Correa ID, Prakash SR, et al. The structure-activity relationship between peroxisome proliferator-activated 
receptor gamma agonism and the antihyperglycemic activity of thiazolidinediones. J Med Chem. 1996;39:665-8.

16. Sun H, Green TA, Theobald DE, Birnbaum SG, Graham DL, Zeeb FD, et al. Yohimbine increases impulsivity through activation of cAMP response element binding in the orbitofrontal cortex. Biol Psychiatry. 2010;67:649-56.

17. Stopponi S, Fotio $Y$, Domi A, Borruto AM, Natividad L, Roberto M, et al. Inhibition of fatty acid amide hydrolase in the central amygdala alleviates co-morbid expression of innate anxiety and excessive alcohol intake. Addict Biol. 2018;23:1223-32.

18. de Guglielmo G, Melis M, De Luca MA, Kallupi M, Li HW, Niswender K, et al. PPARgamma activation attenuates opioid consumption and modulates mesolimbic dopamine transmission. Neuropsychopharmacology. 2015;40:927-37.

19. Tabakoff B, Hoffman PL. Animal models in alcohol research. Alcohol Res Health. 2000;24:77-84.

20. Becker HC, Lopez MF. Increased ethanol drinking after repeated chronic ethanol exposure and withdrawal experience in C57BL/6 mice. Alcohol Clin Exp Res. 2004;28:1829-38

21. Spanagel R. Animal models of addiction. Dialogues Clin Neurosci. 2017:19:247-58.

22. Domi A, Stopponi S, Domi E, Ciccocioppo R, Cannella N. Sub-dimensions of alcohol use disorder in alcohol preferring and non-preferring rats, a comparative study. Front Behav Neurosci. 2019;13:3.

23. Marinelli PW, Funk D, Juzytsch W, Harding S, Rice KC, Shaham Y, et al. The CRF1 receptor antagonist antalarmin attenuates yohimbine-induced increases in operant alcohol self-administration and reinstatement of alcohol seeking in rats. Psychopharmacology. 2007;195:345-55.

24. Stopponi S, Somaini L, Cippitelli A, de Guglielmo G, Kallupi M, Cannella N, et al. Pregabalin reduces alcohol drinking and relapse to alcohol seeking in the rat. Psychopharmacology. 2012;220:87-96.

25. Fibiger HC, LePiane FG, Jakubovic A, Phillips AG. The role of dopamine in intracranial self-stimulation of the ventral tegmental area. J Neurosci. 1987;7:3888-96.

26. Di Chiara G. The role of dopamine in drug abuse viewed from the perspective of its role in motivation. Drug Alcohol Depend. 1995;38:95-137.

27. Koob GF, Volkow ND. Neurobiology of addiction: a neurocircuitry analysis. Lancet Psychiatry. 2016;3:760-73.

28. Luscher C, Malenka RC. Drug-evoked synaptic plasticity in addiction: from molecular changes to circuit remodeling. Neuron. 2011;69:650-63.

29. Di Chiara G, Imperato A. Drugs abused by humans preferentially increase synaptic dopamine concentrations in the mesolimbic system of freely moving rats. Proc Natl Acad Sci USA. 1988;85:5274-8.

30. Volkow ND, Fowler JS, Wang GJ, Swanson JM. Dopamine in drug abuse and addiction: results from imaging studies and treatment implications. Mol Psychiatry. 2004;9:557-69.

31. Schultz W. Getting formal with dopamine and reward. Neuron. 2002;36:241-63.

32. Lecca S, Melis M, Luchicchi A, Muntoni AL, Pistis M. Inhibitory inputs from rostromedial tegmental neurons regulate spontaneous activity of midbrain dopamine cells and their responses to drugs of abuse. Neuropsychopharmacology. 2012;37:1164-76.

33. Jalabert M, Bourdy R, Courtin J, Veinante P, Manzoni OJ, Barrot M, et al. Neuronal circuits underlying acute morphine action on dopamine neurons. Proc Natl Acad Sci USA. 2011;108:16446-50.

34. Polter AM, Barcomb K, Tsuda AC, Kauer JA. Synaptic function and plasticity in identified inhibitory inputs onto VTA dopamine neurons. Eur J Neurosci. 2018;47:1208-18.

35. Lavezzi HN, Zahm DS. The mesopontine rostromedial tegmental nucleus: an integrative modulator of the reward system. Basal Ganglia. 2011;1:191-200.

36. Jhou TC, Fields HL, Baxter MG, Saper CB, Holland PC. The rostromedial tegmental nucleus (RMTg), a GABAergic afferent to midbrain dopamine neurons, encodes aversive stimuli and inhibits motor responses. Neuron. 2009;61:786-800.

37. Ye $\mathrm{JH}, \mathrm{Fu} \mathrm{R}, \mathrm{He} \mathrm{W}$. The rostromedial tegmental nucleus and alcohol addiction. Oncotarget. 2017;8:18624-25.

38. Domi E, Uhrig S, Soverchia L, Spanagel R, Hansson AC, Barbier E, et al. Genetic deletion of neuronal PPARgamma enhances the emotional response to acute stress and exacerbates anxiety: an effect reversed by rescue of amygdala PPARgamma function. J Neurosci. 2016;36:12611-23.

39. Weiss F, Ciccocioppo R, Parsons LH, Katner S, Liu X, Zorrilla EP, et al. Compulsive drug-seeking behavior and relapse. Neuroadaptation, stress, and conditioning factors. Ann N Y Acad Sci. 2001;937:1-26.

40. Stewart J. Stress and relapse to drug seeking: studies in laboratory animals shed light on mechanisms and sources of long-term vulnerability. Am J Addict. 2003;12:1-17.
41. Greenwald MK, Lundahl LH, Steinmiller CL. Yohimbine increases opioid-seeking behavior in heroin-dependent, buprenorphine-maintained individuals. Psychopharmacology. 2013;225:811-24.

42. Umhau JC, Schwandt ML, Usala J, Geyer C, Singley E, George DT, et al. Pharmacologically induced alcohol craving in treatment seeking alcoholics correlates with alcoholism severity, but is insensitive to acamprosate. Neuropsychopharmacology. 2011;36:1178-86.

43. Simms JA, Bito-Onon JJ, Chatterjee S, Bartlett SE. Long-Evans rats acquire operant self-administration of $20 \%$ ethanol without sucrose fading. Neuropsychopharmacology. 2010;35:1453-63.

44. Le AD, Funk D, Coen K, Li Z, Shaham Y. Role of corticotropin-releasing factor in the median raphe nucleus in yohimbine-induced reinstatement of alcohol seeking in rats. Addict Biol. 2013;18:448-51.

45. Le AD, Harding S, Juzytsch W, Funk D, Shaham Y. Role of alpha-2 adrenoceptors in stress-induced reinstatement of alcohol seeking and alcohol selfadministration in rats. Psychopharmacology. 2005;179:366-73.

46. Bossert JM, Marchant NJ, Calu DJ, Shaham Y. The reinstatement model of drug relapse: recent neurobiological findings, emerging research topics, and translational research. Psychopharmacology. 2013;229:453-76.

47. Calu DJ, Chen YW, Kawa AB, Nair SG, Shaham Y. The use of the reinstatement model to study relapse to palatable food seeking during dieting. Neuropharmacology. 2014;76:395-406.

48. Mantsch JR, Baker DA, Funk D, Le AD, Shaham Y. Stress-induced reinstatement of drug seeking: 20 years of progress. Neuropsychopharmacology. 2016;41: 335-56.

49. Chen YW, Fiscella KA, Bacharach SZ, Tanda G, Shaham Y, Calu DJ. Effect of yohimbine on reinstatement of operant responding in rats is dependent on cue contingency but not food reward history. Addict Biol. 2015;20: 690-700.

50. Ball KT, Miller L, Sullivan C, Wells A, Best O, Cavanaugh B, et al. Effects of repeated yohimbine administration on reinstatement of palatable food seeking: involvement of dopamine D1-like receptors and food-associated cues. Addict Biol. 2016;21:1140-50.

51. Brown ZJ, Kupferschmidt DA, Erb S. Reinstatement of cocaine seeking in rats by the pharmacological stressors, corticotropin-releasing factor and yohimbine: role for D1/5 dopamine receptors. Psychopharmacology. 2012;224: 431-40.

52. Nair SG, Navarre BM, Cifani C, Pickens CL, Bossert JM, Shaham Y. Role of dorsal medial prefrontal cortex dopamine D1-family receptors in relapse to high-fat food seeking induced by the anxiogenic drug yohimbine. Neuropsychopharmacology. 2011;36:497-510.

53. Deutch AY, Roth RH. The determinants of stress-induced activation of the prefrontal cortical dopamine system. Prog Brain Res. 1990;85:367-402.

54. Thierry AM, Tassin JP, Blanc G, Glowinski J. Selective activation of mesocortical DA system by stress. Nature. 1976;263:242-4.

55. McFarland K, Davidge SB, Lapish CC, Kalivas PW. Limbic and motor circuitry underlying footshock-induced reinstatement of cocaine-seeking behavior. J Neurosci. 2004;24:1551-60.

56. Bourdy R, Sanchez-Catalan MJ, Kaufling J, Balcita-Pedicino JJ, Freund-Mercier MJ, Veinante $\mathrm{P}$, et al. Control of the nigrostriatal dopamine neuron activity and motor function by the tail of the ventral tegmental area. Neuropsychopharmacology. 2014;39:2788-98.

57. Jhou TC, Geisler S, Marinelli M, Degarmo BA, Zahm DS. The mesopontine rostromedial tegmental nucleus: a structure targeted by the lateral habenula that projects to the ventral tegmental area of Tsai and substantia nigra compacta. J Comp Neurol. 2009;513:566-96.

58. Swanson CJ, Bures M, Johnson MP, Linden AM, Monn JA, Schoepp DD. Metabotropic glutamate receptors as novel targets for anxiety and stress disorders. Nat Rev Drug Discov. 2005;4:131-44.

59. Haller J, Bakos N. Stress-induced social avoidance: a new model of stress-induced anxiety? Physiol Behav. 2002;77:327-32.

60. Belcher G, Lambert C, Edwards G, Urquhart R, Matthews DR. Safety and tolerability of pioglitazone, metformin, and gliclazide in the treatment of type 2 diabetes. Diabetes Res Clin Pract. 2005;70:53-62.

61. Dormandy J, Bhattacharya M, van Troostenburg, de Bruyn AR, investigators PR. Safety and tolerability of pioglitazone in high-risk patients with type 2 diabetes: an overview of data from PROactive. Drug Saf. 2009;32:187-202.

62. Kikuchi M, Kaku K, Odawara M, Momomura S, Ishii R. Efficacy and tolerability of rosiglitazone and pioglitazone in drug-naive Japanese patients with type 2 diabetes mellitus: a double-blind, 28 weeks' treatment, comparative study. Curr Med Res Opin. 2012;28:1007-16. 